\title{
ELECCIONES LEGISLATIVAS EN ITALIA
}

Durante los días 26 y 27 de junio de este año se han celebrado en Italia elecciones legislativas para renovar la Cámara de Diputados (630 diputados) y el Senado ( 315 senadores) y dotar al país del cuarenta y cuatro Gobierno nombrado desde la segunda guerra mundial.

Aunque Italia es uno de los países de Europa con más alto índice de participación electoral, en esta ocasión la abstención casi se duplicó con respecto a las pasadas elecciones de 1979 y ha alcanzado el 18 por 100, mientras que el voto nulo fue el 6,7 por 100. En este sentido hay que señalar que el Partido Radical propugnó durante su campaña electoral la abstención, el voto nulo y/o el apoyo a las listas del propio Partido Radical, como un sufragio contra la partidocracia y de protesta contra el sistema en general, lo que sin duda ha influido en el índice de participación y voto nulo.

Las elecciones italianas de 1983 han sido muy significativas en dos aspectos: por un lado, el fracaso electoral de la Democracia Cristiana y, por otro, lo que podríamos llamar el voto «contra el sistema», representado principalmente por el aumento de sufragios conseguidos por el Movimiento Social Italiano, de tendencia neofascista.

Otro de los beneficiados en estas elecciones ha sido el Partido Republicano, que ha conseguido 14 diputados y cuatro senadores más que en 1979, y en la misma línea, aunque en menor medida, también el Partido Liberal ha visto incrementada su representación tanto en la Cámara de los Diputados como en el Senado.

Con todo, lo más destacable, como ya hemos apuntado, es la derrota de la Democracia Cristiana, que ha perdido en estas elecciones 36 diputados y 18 senadores con respecto a las elecciones de 1979, con lo que ha obtenido el peor resultado de su historia. Aproximadamente un 6 por 100 de su electorado teórico no le ha otorgado su voto en estas elecciones.

En la izquierda, el Partido Comunista ha sufrido un leve retroceso, mientras que el Partido Socialista ha aumentado, también levemente, su representación en la Cámara y en el Senado.

Los resultados de estas elecciones no parecen favorecer la formación de un Gobierno estable y todo parece indicar que habría que repetir la coalición de centroizquierda, cuya falta de coherencia y acuerdo político han provocado estas elecciones anticipadas.

A continuación reproducimos los resultados de estas elecciones legislativas italianas y, comparativamente, los de las pasadas elecciones de 1979: 


\section{CAMARA DE DIPUTADOS}

\begin{tabular}{|c|c|c|c|c|}
\hline & \multicolumn{2}{|c|}{1983} & \multicolumn{2}{|c|}{1979} \\
\hline & $\%$ & Escaños & $\%$ & Escaños \\
\hline Democracia Cristiana $\ldots . . .$. & 32,7 & 224 & 38,3 & 262 \\
\hline Partido Comunista $\ldots \ldots \ldots \ldots$ & 29,7 & 197 & 30,4 & 201 \\
\hline $\begin{array}{ccccc}\text { Partido Socialista } & \ldots & \ldots & \ldots & \ldots\end{array}$ & 11,2 & 72 & 9,8 & 62 \\
\hline Movimiento Social Italiano ... & 7,1 & 45 & 5,3 & 30 \\
\hline $\begin{array}{llll}\text { Partido Socialdemócrata } & \ldots & \ldots & \ldots \\
\end{array}$ & 4,0 & 22 & 3,8 & 20 \\
\hline $\begin{array}{llllll}\text { Partido Republicano } & \ldots & \ldots & \ldots & \ldots\end{array}$ & 5,2 & 30 & 3,0 & 16 \\
\hline $\begin{array}{cccccc} & \\
\text { Partido Liberal } & \ldots & \ldots & \ldots & \ldots & \ldots\end{array}$ & 3,0 & 16 & 1,9 & 9 \\
\hline 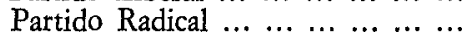 & 2,3 & 12 & 3,5 & 18 \\
\hline Democracia Proletaria ... ... ... ... & 1,5 & 7 & 0,8 & - \\
\hline
\end{tabular}

SENADO

\begin{tabular}{|c|c|c|c|c|}
\hline \multirow[b]{2}{*}{. } & \multicolumn{2}{|c|}{1983} & \multicolumn{2}{|c|}{1979} \\
\hline & $\%$ & Escaños' & $\%$ & Escaños \\
\hline $\begin{array}{llllll}\text { Democracia Cristiana } & \ldots & \ldots & \ldots & \ldots\end{array}$ & 32,4 & 120 & 38,3 & 138 \\
\hline Partido Comunista ................ & 30,6 & 108 & 31,5 & 109 \\
\hline $\begin{array}{llllll} & \\
\text { Partido Socialista } & \ldots & \ldots & \ldots & \ldots & \ldots\end{array}$ & 11,3 & 37 & 10,4 & 32 \\
\hline Movimiento Social Italiano .... ... & 7,5 & 20 & 5,7 & 13 \\
\hline Partido Socialdemócrata $\ldots . .$. & 3,8 & 7 & 4,2 & 9 \\
\hline 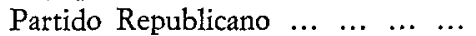 & 4,6 & 10 & 3,4 & 6 \\
\hline Partido Liberal ... ... ... .......... & 2,7 & 5 & 2,2 & 2 \\
\hline $\begin{array}{llllll}\text { Partido Radical } & \ldots & \ldots & \ldots & \ldots & \ldots\end{array}$ & 1,8 & 1 & 2,3 & 2 \\
\hline Democracia Proletaria $\ldots \ldots \ldots \ldots$ & 1,1 & 1 & - & - \\
\hline
\end{tabular}

FueNTE: Datos aportados por la Embajada de Italia en Madrid.

YoLANDA GÓMEZ SÁNCHEZ 